Научная статья

УДК 101.1

DOI: $10.17213 / 2075-2067-2021-6-257-263$

\title{
ИСТОРИЧНОСТЬ В СОЦИАЛЬНОМ ЗНАНИИ: ТЕОРЕТИКО-МЕТОДОЛОГИЧЕСКИЕ ПРОБЛЕМЫ
}

\author{
Павел Викторович Павлов \\ Южнно-Российский государственный политехнический университет (НПИ) \\ имени М. И. Платова, Новочеркасск, Россия \\ pvpavlov2006@yandex.ru, ОRCID: 0000-0002-9700-5136, AuthorID РИНЦ: 402794
}

Аннотация. Целью статьи является анализ проблемы историчности в социальном знании. Исследуется дуализм исторического и социологического типов познания общественной реальности; особое место отводится проблеме социальных структур и социальных изменений.

Методология исследования. Статья базируется на конкретно-исторической методологии, в свете которой рассмотрены противоречия социального знания и его становления.

Результаты исследования. Историчность является фундаментальной характеристикой сочиальной реальности, а также методологическим принципом ее исследования. В статье делается вывод об актуальности конкретно-исторической методологии, в свете которой возможно адекватное понимание социальных трансформаций в их сложности и противоречивости.

Ключевые слова: историчность, сочиальное знание, история, сочиология, социальные структуры, социальные изменения, конкретно-историческая методология

Для цитирования: Павлов П.В. Историчность в сочиальном знании: теоретикометодологические проблемы//Вестник Южно-Российскогогосударственного технического университета. Серия: Социально-экономические науки. 2021. T. 14, №6. C. 257-263. http:// dx.doi.org/10.17213/2075-2067-2021-6-257-263.

Original article

\section{HISTORICITY IN SOCIAL KNOWLEDGE: THEORETICAL AND METHODOLOGICAL PROBLEMS}

\author{
Pavel V. Pavlov \\ Platov South Russian State Polytechnic University (NPI), Novocherkassk, Russia \\ pvpavlov2006@yandex.ru, ORCID: 0000-0002-9700-5136, AuthorID RSCI: 402794
}

Abstract. The purpose of the study is to analyze the problem of historicity in social knowledge. The dualism of historical and sociological types of cognition of social reality is investigated; a special place is given to the problem of social structures and social changes.

Research methodology. The article is based on a concrete historical methodology, in the light of which the contradictions of social knowledge and its formation are considered.

(C) Павлов П.В., 2021 
Research results. Historicity is a fundamental characteristic of social reality, as well as a methodological principle of its research. The article concludes about the relevance of a concrete historical methodology, in the light of which an adequate understanding of social transformations in their complexity and contradictions is possible.

Keywords: historicity, social knowledge, history, sociology, social structures, social change, concrete historical methodology

For citation: Pavlov P.V. Historicity in social knowledge: theoretical and methodological problems // Bulletin of the South Russian State Technical University. Series: Socio-economic Sciences. 2021; 14(6): 257-263. (In Russ.). http://dx.doi.org/10.17213/2075-2067-2021-6-257-263.

Введение. Интерес к проблеме «истории» и «историчности» в социальных науках и современном социальном знании - тенденция, проявляющаяся в самых различных «ипостасях». Это многочисленные исследования «исторической памяти», инициированные влиянием известных работ М. Хальбвакса [6] и Я. Ассмана [1] или же исследования в области такого направления, как «историческая социология». Так, Ричард Лахман в свете «исторической социологии» анализирует проблемы генезиса капитализма, социальных движений и революций, проблемы государств и империй, а также проблемы неравенства, семьи и культуры [4].

Р. Лахман говорит о том, что социология, стремясь объяснить социальные изменения, изначально была «исторической дисциплиной». При этом он обращается к «основателям социологии» - К. Марксу, М. Веберу и Э. Дюркгейму. Впрочем, «социология» впервые основана позитивистом О. Контом, и его «социология» принципиально отлична как от материалистического понимания истории Маркса, его конкретно-исторической методологии, так и «понимающей социологии» М. Вебера. Именно позитивистский и по сути неисторический подход, восходящий к Конту, стал доминирующей тенденцией в западной социологической науке прежде всего, в знаменитом структурном функционализме Толкотта Парсонса. Структурный функционализм Парсонса как раз и стал той «парадигмой», которая на долгие десятилетия определила исследовательские схемы в социальных науках (и во многом продолжает определять и по сей день). И если сейчас говорят о своего рода «переоткрытии» истории в социальных науках, то до недавнего времени история изгонялась из социологических теорий, происходило своего рода ее «забвение».

Дуализм «исторического» и «социологического» типов познания. Действительно, длительное время социальные науки - прежде всего, социология и ее ответвления (если не считать такие значимые исключения, как «понимающая социология» М. Вебера) во многом противостояли историческим или гуманитарным наукам во главе соответственно с историей, которая в XIX веке приобретает свое теоретическое самосознание. В связи с этим вполне уместно говорить о дуализме исторического и социологического способов познания. При этом речь идет не только и даже не столько о противостоянии социологии и истории как конкретных научных дисциплин, а о более широком противостоянии социологического и исторического типов познания общественной действительности. В чем сущность этого противостояния и специфика указанных способов познания?

Как известно, исторически социология и соответственно социологический тип познания формировались в рамках позитивизма с его сциентизмом, ориентацией на точные научные дисциплины и естествознание, которое в те времена по существу являлось механистичным. Характерно, что основатель позитивизма Огюст Конт в качестве синонима придуманного им термина «социология» использовал термин «социальная физика». Термину «социальная физика» соответствовало и его содержание, сущность которого можно выразить как принципиальный антиисторизм. Конечно, характеризуя свою «социологию», Конт не только говорит о социальной статике, но и о социальной динамике, которая сводится им к «закону трех стадий» 
в развитии человечества, увенчанного идеалом позитивного общества. Эти стадии развития - теологическая, метафизическая и позитивная - в лучшем случае интерпретируют историю как прямолинейное, поступательное движение, как монотонный «прогресс», лишенный подлинного исторического драматизма. И это означает, что «социальная динамика» не схватывает противоречивую целостность исторического процесса, его богатства и многообразия, а потому остается абстрактной и по существу статичной схемой. Впрочем, и сами понятия статики и динамики заимствуются Контом из современной ему физики.

Натуралистическая установка в понимании общественной реальности отчетливо прослеживается и у Г. Спенсера, последователя Конта. Однако если контовский натурализм апеллировал к физике, то для Спенсера моделью общественного познания служит биология. Спенсер, по большому счету, редуцирует общество к биологическому организму, наделенного «структурой» и «функциями», и тем самым предвосхищает позднейшую структурно-функциональную социологию. При таком подходе социальная реальность, выступая наподобие биологического организма, также оказывается неисторичной, ограниченной гомеостатическим равновесием.

В связи с этим существенным методологическим принципом позитивистской социологии оказывается нацеленность на анализ структуры общества, а не на его историю. Как отмечает Ж. Гурвич, социология, используя в качестве метода типологию социальных феноменов и их структур, стремится сопоставить историческую реальность с «неисторическими (или почти не историческими) социальными рамками» [2, с. 273]. Впрочем, точнее было бы сказать, что социология пытается втиснуть историческую реальность в неисторические рамки. Но в этом как раз и заключается парадокс позитивистской социологии: общество, будучи по своей сути «пронизанным историчностью», изучается принципиально не исторично.

Именно в противоположность позитивистскому сциентизму и социологизму возникла методология «наук о духе» (гуманитарных наук), которая явилась рефлексией на становление теоретического самосозна- ния исторических наук. Эта методология представлена, прежде всего, психологическим историзмом В. Дильтея, а затем исследованиями баденской школы неокантианства (В. Виндельбанд, Г. Риккерт). Причем интерес неокантианцев к историческим наукам был не случаен: если И. Кант попытался ответить на вопрос, как возможны математика и естествознание (ньютоново), то во времена неокантианцев остро встал вопрос о возможности исторического познания, своего рода вопрос о «критике исторического разума». Как известно, Дильтей, а за ним Виндельбанд и Риккерт резко противопоставили «науки о природе» (Naturwissenschaften) и «науки о духе» (Geistwissenschaften). Соответственно этому различению как раз и возникли знаменитые методологические оппозиции «объяснение - понимание», «номотетическое - идиографическое», «генерализация индивидуализация».

В начале XX века о принципиальной разнице природы и истории говорил и О. Шпенглер в своем известном труде «Закат Европы». По его мнению, действительность в сознании субъекта раскалывается на «мир как историю» и на «мир как природу». История - это сфера становящегося, уникального, неповторимого, живого и временного. Об истории по существу не может быть строгого научного знания. «Мир как природа», по Шпенглеру, напротив, - это ставшее, мертвое, механическое, пространственное, а потому поддающееся математическому исчислению и научному рассудку вообще.

Вместе с тем уже во времена Дильтея, Риккерта и Шпенглера обозначилась не только оппозиция «наук о духе» и «наук о природе», но и явственно выявился дуализм самого социального познания, один полюс которого был представлен натурализмом и сциентизмом социологии, а другой - индивидуализирующим историзмом гуманитарных наук. Оппозиции «номотетическое» - «идиографическое», «генерализация - индивидуализация» стали реальностью внутри самих общественных наук. Обозначим существенные методологические аспекты оппозиции исторического и социологического способов познания, которые по большому счету имеют место и в современной социальной рефлексии. 
Прежде всего, история понимается как такая дисциплина, которая нацелена на единичное, уникальное, неповторимое (впрочем, еще Аристотель в своей «Поэтике» указывал на то, что история «говорит о единичном»). Метод исторического познания - индивидуализация, понимание (Verstehen). В свою очередь, социология позиционирует себя в качестве «социальной физики», ориентированной на «номотетическое» естествознание. Такая эмпирико-позитивистская социология нацелена на абстрактно-всеобщий, структурно-статический момент общественной реальности. Ее метод - абстрактная генерализация и такое же формальное «объяснение» эмпирических социальных фактов; она не интересуется уникальными историческими событиями и игнорирует качественные социальные изменения, довольствуясь статическим общественным равновесием.

Этот дуализм социологического и исторического способов познания оказался столь явственным и драматичным, что многие историки и даже социологи во второй половине XX века заговорили о необходимости объединения социологии и истории. Так, известный историк Ф. Бродель пишет о возможном единстве истории и социологии, а социолог Ж. Гурвич требует «прийти к братскому, действенному и плодотворному сотрудничеству социологии и истории», которые, по его мнению, должны «руководить интеграцией всех социальных наук в рамках единой "Науки о Человеке"» [2, с. 282].

Однако помимо позитивистской социологии и индивидуализирующего историзма «наук о духе» существовала целостная методология социально-исторического познания, представленная материалистическим пониманием истории К. Маркса. Суть этого понимания, этой конкретно-исторической методологии заключается в том, что «люди сами творят собственную историю», что они одновременно авторы и актеры собственной исторической драмы. При этом Маркс никогда и нигде не именовал свой подход «социологией», и даже более того - не очень (мягко говоря) жаловал и самого изобретателя этого термина - Огюста Конта. Однако и с социологией дело обстоит не так просто. В первой половине XX века появился уникальный вариант «социологии», не имеющий ничего об- щего с ее позитивистской версией. Речь идет о «понимающей социологии» М. Вебера.

\section{Структуры, социальные изменения} и историчность. Хотя К. Маркс и М. Вебер сегодня признаны классиками социологии (наряду с Э. Дюркгеймом), ирония истории состоит в том, что «поствеберовская» социологическая мысль в лице структурно-функциональной школы Т. Парсонса [5] отказалась от этого классического наследия и по существу возродила позитивистскую социологию с ее структурализмом и натурализмом. Конечно, с формальной точки зрения Парсонс стремился объединить подходы Вебера и Дюркгейма, однако он и его школа по большому счету возвратились к спенсеровскому пониманию общества как биологического организма, обладающего структурой и функциями. Так, согласно Парсонсу систематическая теория социологии должна быть аналогична «структурно-функциональному типу», который характерен для биологии. В этом состоит парсоновский натурализм.

Впрочем, для Парсонса, как и для представителей логического позитивизма, идеалом науки служит физика. Но не только натурализм (конкретнее, физикализм) сближает структурно-функциональную теорию с логическим эмпиризмом. И здесь, и там речь идет об общем методологическом подходе к познанию, а именно - о формальном структурализме. Можно даже сказать, что концепции логического позитивизма явились гносеологической базой структурно-функциональной социологии. Подобно тому, как логический эмпиризм претендовал на обоснование унифицированной методологии естественнонаучного познания, структурно-функциональная теория Парсонса претендовала на построение единой системы социального знания и определенное время была господствующей в странах западного мира. И лишь в 60-е годы XX столетия позитивистская социология начинает подвергаться разносторонней концептуально-методологической критике.

Одним из непосредственных оппонентов структурно-функциональной методологии выступил, как известно, Ральф Дарендорф [3], автор теории социальных изменений. Он вполне справедливо отмечает, что Т. Парсонс не проводит содержательного различия меж- 
ду органическими системами и собственно человеческим обществом. Если для органических систем характерно стремление к поддержке собственного равновесия (гомеостаз), то специфика общества заключается в его историчности, способности выхождения за пределы наличных структур и функций. Ясно, что если речь идет об уподоблении общества организму, то проблема историчности, качественных социальных изменений отпадает: социальность превращается в равновесную систему, стремящуюся к своей стабильности. В такой равновесной (гомеостатической) модели общества изменения признаются лишь постольку, поскольку они направлены на поддержание существующей системы, и в этом смысле такие изменения оказываются абстрактными. Как иронически пишет Дарендорф, люди «рождаются, социализируются и распределяются по ролям, наконец умирают»; и этот процесс циклически повторяется. «Что за тихий, что за идиллический мир эта система!» [3, с. 344].

Естественно, что равновесная модель общества несостоятельна не только с теоретико-методологической точки зрения, но и с социальной. По большому счету эта модель служит оправданием и увековечиванием «status quo», оборачивается, по словам Дарендорфа «ангажированностью на стороне status quo» [3, c. 352].

В противовес «утопическому» обществу структурно-функциональной социологии Р. Дарендорф выдвигает динамическую («историческую») модель общества. При этом в основе общественной динамики, по Дарендорфу, лежит социальный конфликт, понимаемый им в контексте властных отношений и принуждения. Характеризуя свою конфликтную модель общества, Дарендорф пишет, что с точки зрения «этой модели общества сплачиваются не посредством консенсуса, а с помощью принуждения, не через всеобщее согласие, а путем контроля одних над другими...» [3, с. 357]. Именно социальные конфликты обеспечивают «исторические изменения», формируя «человеческий смысл истории». Как подчеркивает Дарендорф, общества «человечны» в той степени, в какой они «поддерживают жизненность противоречий» [3, с. 375].

Критика Дарендорфом «утопической» равновесной модели общества остроумна и во многом верна. Однако, когда он абсолютизирует конфликт и принуждение, ставя их во главу угла социальных изменений, возникают серьезные вопросы. Ведь в основе человеческой культуры и общественно-исторических изменений как таковых лежит все богатство и многообразие способов человеческой деятельности, по отношению к которым конфликт является производным, а вовсе не основным моментом. Способы человеческой деятельности действительно противоречивы, они поляризуются, производя социальные трансформации, однако не всякую такую полярность можно определять в терминах конфликта и принуждения.

Человеческая деятельность, ее способы и формы настолько многообразны и разнонаправлены, что их невозможно редуцировать ни к всеобщему согласию, против которого выступает Дарендорф, ни ко всеобщему конфликту. Если же конфликт тотален, «вездесущ», как это утверждает Дарендорф, то выкладки «вульгарного социологизма», рассматривающего все разнообразие человеческой культуры в качестве проявлений интересов той или иной конфликтующей социальной группировки, неизбежны. Человеческое общество при таком одностороннем подходе превращается в арену борьбы за место под солнцем, в «войну всех против всех».

Впрочем, Дарендорф не склонен переоценивать свою «конфликтную модель», и в конечном счете он пытается в духе метода дополнительности как-то примирить свою модель с равновесной моделью общества. «Насколько я вижу, - пишет он, — для объяснения социологических проблем нам необходима как равновесная, так и конфликтная модель общества; и может быть, в философском анализе у человеческого общества всегда два лица, наделенных одинаковой реальностью: одно лицо - стабильности, гармонии и консенсуса, а другое - изменения, конфликта и принуждения» [3, с. 358]. Однако Дарендорф останавливается на этой констатации и не пытается найти действительное опосредование, нечто «третье» между указанными крайностями, указывая на то, что «с философской точки зрения трудно разглядеть, какие могут быть модели общества, не относящиеся ни к равновесному, ни к конфликтному типу» [3, с. 358]. А между тем таким «третьим» всякий раз ока- 
зывается конкретно-историческая методология, вскрывающая сложность, противоречивость и драматизм социальных процессов.

Заключение. Проблема историчности в социальном знании, конечно, не ограничивается попытками преодоления дуализма «социологического» и «исторического», не исчерпывается попытками заново «открыть» историчность в социальных науках. Однако принципиально важным является понимание того, что, по словам Р. Дарендорфа, «человеческое общество должно быть историчным, то есть постоянно стремиться к новым решениям» [3, с. 375]. Однако социология в своих конструкциях постоянно упускает «живую реальность истории» [3, с. 380], что является «органическим недостатком социологии», который во многом и «является источником постоянно возникающих разногласий между историками и социологами» [3, с. 380]. Современные тенденции «поворота» к историчности, ее «переоткрытие» в социальных науках, в том числе в рамках «исторической социологии», можно, конечно, только приветствовать. Другое дело, является ли этот «исторический поворот» той конкретно-исторической методологией, которая способна исследовать действительные противоречия социальной реальности и ее трансформации? По крайней мере, выраженная Ричардом Лахманом задача - «сосредоточиться на понимании того, как социологический анализ исторического изменения позволяет нам понять как истоки современного мира, так и объем и последствия текущих трансформаций» $[4$, c. 20] - остается актуальной.

\section{Список источников}

1. Ассман Я. Культурная память: Письмо, память о прошлом и политическая идентич- ность в высоких культурах древности. М.: Языки славянской культуры, 2004. 368 с.

2. Гурвич Ж. Диалектика и социология. Краснодар: КубГУ, 2001. 294 с.

3. Дарендорф Р. Тропы из утопии: Работы по теории и истории социологии. М.: Праксис, 2002. $536 \mathrm{c}$.

4. Лахман Р. Что такое историческая социология? М.: Издательский дом «Дело» РАНХиГС, 2016. $240 \mathrm{c.}$

5. Парсонс Т. О социальных системах. М.: Академический проект, 2002. 832 с.

6. Хальбвакс М. Социальные рамки памяти. М.: Новое издательство, 2007. 348 с.

\section{References}

1. Assman Ja. Kul'turnaja pamjat': Pis'mo, pamjat' o proshlom i politicheskaja identichnost' v vysokih kul'turah drevnosti [Cultural memory: Writing, memory of the past and political identity in the high cultures of antiquity]. Moscow: Jazyki slavjanskoj kul'tury, 2004. 368 p. (In Russ.).

2. Gurvich Zh. Dialektika i sociologija [Dialectics and Sociology]. Krasnodar: KubGU, 2001. 294 p. (In Russ.).

3. Darendorf R. Tropy iz utopii: Raboty po teorii i istorii sociologii [Paths from Utopia: Works on Theory and History of Sociology]. Moscow: Praksis, 2002. 536 p. (In Russ.).

4. Lahman R. Chto takoe istoricheskaja sociologija? [What is Historical Sociology?] Moscow: Izdatel'skij dom «Delo» RANHiGS, 2016. 240 p. (In Russ.).

5. Parsons T. O social'nyh sistemah [About social systems]. Moscow: Akademicheskij proekt, 2002. 832 p. (In Russ.).

6. Hal'bvaks M. Social'nye ramki pamjati [Social framework of memory]. Moscow: Novoe izdatel'stvo, 2007. 348 p. (In Russ.).

Статья поступила в редакиию 25.12.2021; одобрена после рецензирования 26.12.2021; принята к публикации 28.12.2021.

The article was submitted on 25.12.2021; approved after reviewing on 26.12.2021; accepted for publication on 28.12.2021. 


\section{ИНФОРМАЦИЯ ОБ АВТОРАХ}

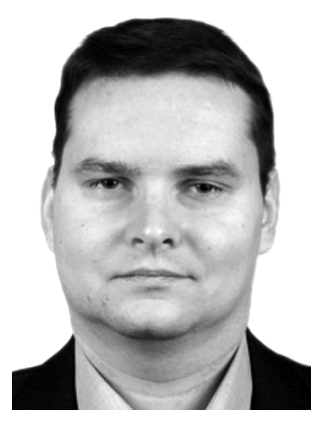

Павлов Павел Викторович - доктор философских наук, профессор кафедры «Социальные и гуманитарные науки» Южно-Российского государственного политехнического университета (НПИ) имени М. И. Платова.

Россия, г. Новочеркасск, ул. Просвещения, 132

Pavel V. Pavlov - Doctor of Philosophical Sciences, Professor, Department of Social Sciences and Humanities, Platov SouthRussian State Polytechnic University (NPI).

132 Prosveshcheniya st., Novocherkassk, Russia 